\title{
Modeling the Integrated Expansion of the Canadian and US Power Sectors
}

\author{
Eduardo Ibanez \\ GE Energy Consulting \\ Schenectady, NY - USA \\ eduardo.ibanez1@ge.com
}

\author{
Owen Zinaman \\ National Renewable Energy Laboratory \\ Golden, CO - USA \\ owen.zinaman@nrel.gov
}

\begin{abstract}
This paper presents the development effort that created a robust representation of the combined capacity expansion of the U.S. and Canadian electric sectors within the NREL ReEDS model. The abbreviated scenario analysis effort was designed to understand drivers behind various CanadianU.S. power sector futures out to 2036. We model the impact of natural gas prices, increased Canadian hydropower deployment, and increased renewable energy (RE) penetrations. The sample results analyzed in this paper show the highly dynamic nature of the modeling tool as it performs a simultaneous optimization of the two countries' generation portfolios. The interactions between the two countries go beyond energy generation and also include firm capacity contracts and renewable energy certificates (RECs). The reference scenario results show a significant increase in wind generation in both the United States and Canada with a gradual retirement of coal and nuclear energy. The evolution of net energy and firm capacity exchange was very dynamic through the span of the analysis period and drives significant investment in transmission capacity across the border, almost doubling the existing capacity of transmission lines. The exchange of energy was driven by regional stories. ISO-NE and NYISO import energy throughout the analysis period. However, in the Western Interconnection we observed increasing imports to Canada from the United States, whereas the exchanges with MISO switched directions.
\end{abstract}

\section{INTRODUCTION}

The United States and Canada share an important electricity relationship, physically interconnected at over 35 points at the high-voltage level from New England to the Pacific Northwest (CEA, 2010). This integration of electricity resources allows for greater coordination, higher levels of reliability, and significant opportunity for expanding access to affordable, low-carbon energy.

In this paper, we document a development effort to update an endogenous treatment of the integrated U.S. - Canada electricity sectors in the NREL Regional Energy Deployment System (ReEDS) model. This effort is thoroughly documented in Martinez et al. (2013) and Zinaman et al. (2015). We also present results from an abbreviated scenario analysis, using this endogenous treatment, which demonstrates the new capability and yields initial insights into the influence of various drivers on power sector deployment. None of the scenarios presented are intended to be a forecast or prediction. The sample results analyzed in this report are intended to demonstrate the newly established capability and illustrate the highly dynamic nature of the modeling tool as it performs a simultaneous optimization of the two countries' generation portfolios.

The remainder of the paper is organized as follows: Section II introduces the ReEDS model, Section III present the data sources used to build the model, Section IV presents the list of scenarios modeled in this study, Section V summarizes results and Section VI concludes.

\section{REgional ENERGy DePloyment System MOdeL}

Modeling future renewable energy scenarios requires tools that can accommodate the diversity of the various renewable energy technologies and applications, the location-dependent quality of many of these resources, and the inherent variability and uncertainty of wind and solar generation. Although no modeling tool can meet all needs simultaneously, ReEDS is the analytical backbone of many NREL studies that involve capacity expansion, including the U.S. Department of Energy (DOE) 20\% Wind Energy by 2030 study (DOE 2008), DOE SunShot Vision Study (DOE 2012), the Renewable Electricity Futures Study (NREL 2012), DOE Wind Vision Study (DOE 2015) and others (Logan et al. 2013, and Mai et al. 2013). For detailed documentation of an earlier version of the model, see Short et al. (2011).

ReEDS is a generation and transmission capacity expansion model of the electricity system of the contiguous United States and, through. ReEDS is unique among nationwide and long-term capacity expansion models for its highly discretized regional structure and statistical treatment of the impact of variability of wind and solar resources on capacity planning and dispatch.

More specifically, ReEDS is a linear program that minimizes overall electric system costs subject to a large number of constraints. The major constraints include meeting electricity demand within specific regions, regional resource supply limitations, planning and operating reserve 
requirements, state and federal policy demands, and transmission constraints. To satisfy these constraints, the ReEDS optimization routine chooses from a broad portfolio of conventional generation, renewable generation, storage, and demand-side technologies (see Table I), including the deployment location of these technologies. Additionally, because of its detailed regional and temporal representation, ReEDS can estimate the costs of transmission expansion and operational integration and has a simplified representation of transmission power flow.

TABLE I. GENERATION, STORAGE, AND DEMAND TECHNOLOGIES CONSIDERED IN REEDS

\begin{tabular}{ll}
\hline \multicolumn{1}{c}{ Category } & \multicolumn{1}{c}{ Technologies } \\
\hline Genventional & Pulverized coal \\
& Natural gas combined cycle ${ }^{\mathrm{a}}$ \\
& Natural gas combustion turbine \\
& Nuclear \\
& Integrated gasification combined cycle ${ }^{\mathrm{a}}$ \\
\hline Renewable & Onshore wind \\
Generation & Offshore wind \\
& CSP with and without thermal storage ${ }^{\mathrm{b}}$ \\
& Utility-scale and distributed rooftop PV ${ }^{\mathrm{c}}$ \\
& Dedicated and co-fired biomass \\
& Geothermal \\
& Hydropower \\
& Ocean \\
\hline Storage & Pumped storage hydropower \\
& Compressed air energy storage \\
& Batteries \\
\hline Demand-Side & Thermal energy storage in buildings \\
Technologies & Interruptible load \\
& Utility-controlled PEV charging \\
\hline
\end{tabular}

a. Carbon capture and storage version of these technologies are also implemented in ReEDS b. CSP is Concentrated Solar Powe c. $\mathrm{PV}$ is photovoltaics d. PEV is Plug-in Electric Vehicle

The capacity expansion and dispatch decision making of ReEDS considers the net present value cost of adding new generation capacity and operating it (considering transmission and operational integration) over an assumed financial lifetime (20 years). This cost-minimization routine was applied for each 2-year investment period from 2010 until 2050. As a cost-optimization model, ReEDS does not attempt to capture non-economic (e.g., behavioral, social, institutional) considerations in its investment and dispatch decision-making routine. These noneconomic factors can be significant, particularly regionally, and further work is necessary to quantify their impacts.

ReEDS represents the contiguous United States using 403 wind and concentrating solar power (CSP) resource regions (356 in the United States and 47 in Canada). These resource supply regions are grouped into four levels of larger regional groupings: balancing areas (BAs), reserve-sharing groups, North American Electric Reliability Council (NERC) regions (NERC, 2010) [6], and interconnects. This level of geographic detail, depicted in Fig. 1, enables the model to account for geospatial differences in resource quality, transmission needs, electrical (grid-related) boundaries, political and jurisdictional boundaries, and demographic distributions. In ReEDS, BAs are the regional areas within which demand requirements must be satisfied. Although existing BA authority boundaries were considered in the design of the BAs, the BA boundaries are often not aligned with the boundaries of real BA authorities to accommodate other aforementioned boundaries (e.g., political boundaries). There are 154 BAs in ReEDS, with 134 in the United States and 20 in Canada.

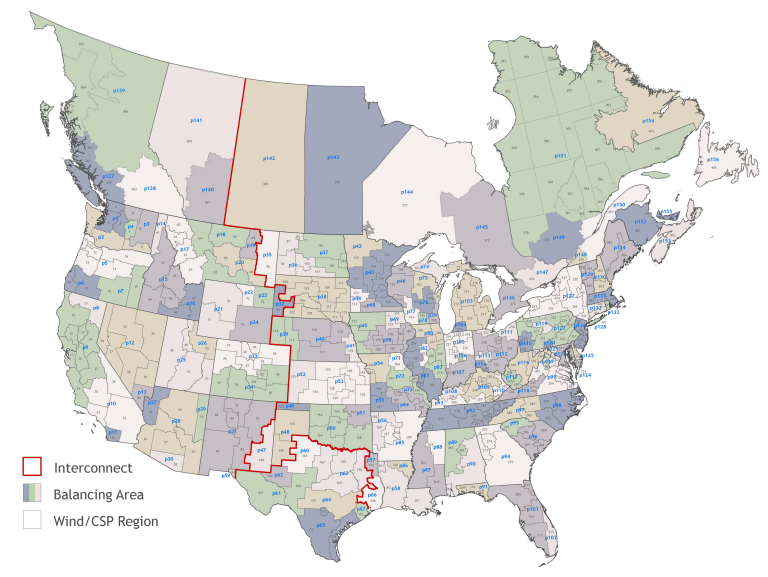

Figure 1. ReEDS regions showing the different aggregation levels.

ReEDS dispatches generation within 17 time slices (four time slices for each season representing morning, afternoon, evening, and nighttime, with an additional summer-peak time slice). This level of temporal detail-though not as sophisticated as that of an hourly chronological dispatch model-enables ReEDS to consider seasonal and diurnal changes in demand and resource availability. Fig. 2 compares a typical load duration curve and the discretized version based on the 17 time slices. Moreover, because significant demand and resource variations can occur within each time slice, ReEDS uses statistical calculations to estimate the capacity value, forecast error reserves, and curtailment of wind and solar resources; these calculations also consider the correlations of output profiles between projects of the same type in different locations, between projects that rely on different resource types, and between different regional demand profiles.

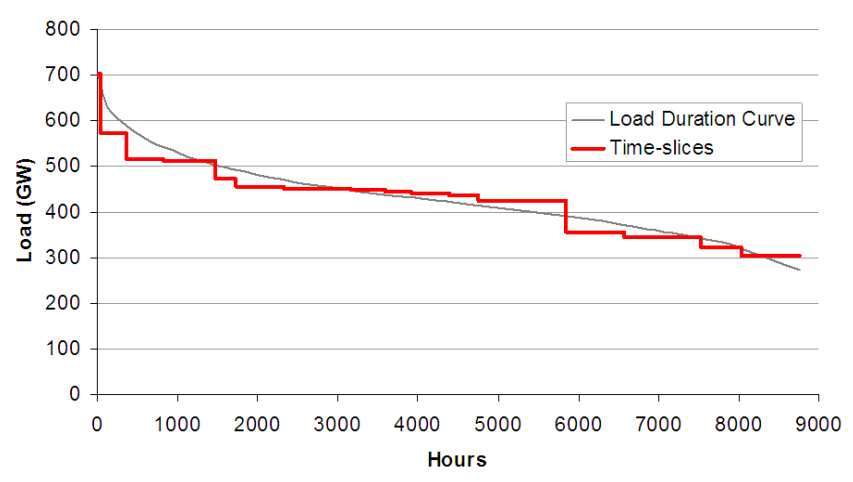

Figure 2. Discretization of the load duration curve utilizing the 17 time slices defined in ReEDS.

The statistical calculations in ReEDS are used in multiple reserve and load balancing constraints in the model. At the longest timescales, ReEDS enforces a planning reserve 
requirement that ensures there is sufficient generating capacity to exceed the annual forecasted peak demand hour by the requisite reserve margin, which ranges from $12.5 \%$ to $17.2 \%$. At shorter hourly to sub-hourly timescales relevant to daily electric system operations, ReEDS requires sufficient supplyand demand-side technologies to satisfy operating reserve requirements. The operating reserves considered in ReEDS included wind and solar forecast error reserves, contingency reserves, and frequency regulation. Because contingency reserves and frequency regulation requirements were assumed to be established as a fraction of demand (6\% for contingency and $1.5 \%$ for frequency regulation), they were independent of the amount of variable generation. In contrast, forecast error reserve requirements were estimated based on hourly persistence forecasts for wind and solar PV, and therefore increased as variable generation increased. ReEDS does not directly capture the wear-and-tear costs associated with operating the conventional thermal power plant fleet in a more flexible fashion. Additional research on these costs and their implications for renewable energy integration is warranted.

In ReEDS, planning and operating reserves were assumed to be maintained independently in reserve sharing groups for all years of the study period, representing greater cooperation over larger areas than exists in the current grid. Existing regional transmission organizations and independent system operators (such as Midwest ISO, New England ISO, PJM, or California ISO) were used in the construction of some of the reserve sharing groups; where there was no existing regional transmission organization or independent system operator, a future reserve-sharing region was assumed. Some of these reserve-sharing groups were larger than those that currently operate under the assumption that additional market integration and transmission expansion over the next 40 years would expand current reserve-sharing regions.

For transmission, existing transmission infrastructure was assumed to continue to be operable throughout the study period, and existing line capacity was assumed to be usable by both conventional and renewable generation sources. The regional resolution of the ReEDS model allows it to roughly estimate new transmission expansion needs and associated investment requirements. The ReEDS model's deployment decision-making algorithm is able to compare the total system costs, including costs of additional required transmission infrastructure, of distant but higher quality renewable resources with more local but lower quality resources, based on generation and transmission cost considerations. In addition to the expansion of long-distance transmission lines, interconnection costs for new generation and storage technologies were considered in ReEDS. For wind and CSP technologies, additional interconnection supply curves were applied to account for the strong location dependence of those resources, yielding total interconnection costs for these technologies that were generally greater than for other technologies. A detailed description of these supply curves and the transmission treatment in ReEDS is provided in Short et al. (2011). Implicit in the ReEDS treatment of transmission is that new transmission can be built within and between regions to enable access to renewable resources and leverage geospatial, temporal, and technological diversity between resources.

These measures ensure that ReEDS results are as detailed geographically and temporally as computational constraints allow, while also being consistent with an electricity system that is able to maintain an overall balance between supply and demand. In sum, ReEDS provides a means of estimating the type and location of conventional and renewable resource development; the transmission infrastructure expansion requirements of those installations; and the composition and location of generation, storage, and demand-side technologies needed to maintain balance between supply and demand. Additional detail on ReEDS can be found in Short et al. (2011).

\section{DATA SOURCES}

The creation of a model with the scope of ReEDS requires a large number of assumptions to drive simulations. This section summarizes the primary sources of data, with a special focus on the Canadian system. The assumptions for the U.S. portion of the system are documented in NREL (2014). A more thorough description of these sources is included in Zinaman et al. (2015).

Natural gas supply and demand dynamics are represented in ReEDS through regional supply curves along Energy Information Administration (EIA) Census Region boundaries. These supply curves are derived from Annual Energy Outlook (AEO) 2014 (EIA 2014). For Canadian provinces, we modify the U.S.-only regional supply curves based on consumption projections from National Energy Board's Canada's Energy Future 2013 (NEB 2013). Natural gas supply curves are modified to capture the additional supply and demand for natural gas in Canadian regions; geographically adjacent Canadian provinces are assigned to EIA Census Regions (see Fig. 3). Canadian coal prices are provincial and represented as inelastic to changes in consumption; they are consistent with Canadian provincial coal price projections from NEB (2013). The price of nuclear fuel for Canadian units is assumed to be consistent with the AEO 2014 Reference Case data for the United States (EIA 2014).

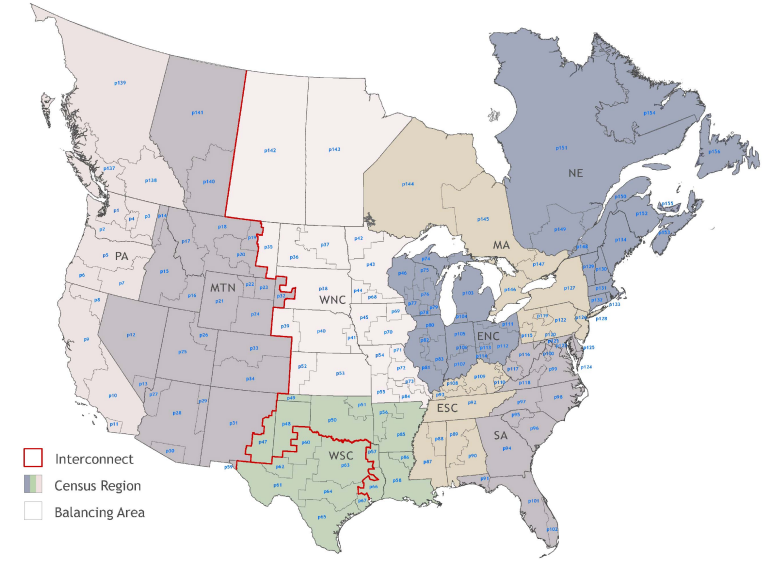

Figure 3. Map of EIA Census Region boundaries extended to Canadian provinces 
Annual electricity demand projections were updated to the NEB (2013) reference scenario, and reflects annual provincial load reduced by customer-sited electricity cogeneration. Provincial and zonal load shapes were documented in Martinez et al. (2013).

Conventional generation data, including existing capacity, and expected retirements and future additions are based on data from the Ventyx Energy Velocity Suite (Ventyx Energy 2014). This data set is then cross-referenced with NEB (2013), Ontario’s Long Term Energy Plan (OME 2013) and other regional reports. Assumed cost and performance characteristics for conventional power plant technologies are consistent with the EIA's AEO 2014 Reference Case (EIA 2014) and other sources in NREL (2014). Hydropower capacity is based on a schedule of expected builds from NEB (2013). Only builds from NEB (2013) that reflect specific projects (as opposed to general expectations of new construction) are prescribed.

Wind cost and performance projections are based on an NREL (2014). Potential wind plant locations are grouped into techno-resource groups (TRGs) for representation in the ReEDS model. TRGs are designed to bin the total resource pool by the average wind speed and assumed turbine technologies by region. There are five TRGs for land-based wind technology and 10 TRGs for offshore wind technology, representing three different depth deployment technologies. A more detailed description of TRGs is presented in DOE's Wind Vision study (DOE 2015). The potential U.S. wind resource is subject to standard exclusions. A complete list of these exclusions is available in Lopez et al. (2012). The Canadian wind resource is classified by TRG based on geographical information of average wind speed (Environment Canada 2008), which is converted based on a classification method detailed in Zinaman et al (2015).

Utility-scale photovoltaic (PV) cost and performance assumptions are based on NREL (2014). Solar insolation data is obtained from Canadian Weather year for Energy Calculation (CWEC) (2013), a data set comprising twelve typical meteorological months (derived from almost 30 years of data) from 80 weather stations throughout Canada (Environment Canada 2014). Average insolation data was then aggregated to the ReEDS BA level and applied in the System Advisor Model (SAM) to create hourly output profiles for a representative utility-scale PV plant (Blair et al. 2014). Hourly plant output from SAM is then aggregated to ReEDS time slice granularity and applied in the model.

ReEDS represents all existing, mandatory state RPS. We model the impact of RPS programs in 28 U.S. states, the District of Columbia, Nova Scotia and British Columbia, including solar RPS carve-out requirements in 12 U.S. states. Each of the RPS requirements is assumed to be fully met unless an alternative compliance payment is endogenously selected to be made.

Renewable energy certificates (RECs) are represented as technology-specific in ReEDS, and can be purchased and retired across select states, as aligned with current laws, regulations and practices for interstate trading and RPS technology eligibility. Banking and borrowing of RECs between solve years is not modeled. All out-of-state REC purchases are required to be associated with delivered, technology-eligible renewable power. Canadian contributions to U.S. state RPS (and vice versa) are permitted in alignment with existing laws, regulations and practices as of October 2014. We list the rules for U.S. - Canada REC trading in Table II, focusing on U.S. states that are physically or electrically adjacent to a Canadian province, or where international REC trading activity has been observed in practice.

TABLE II. INTERNATIONAL REC TRADING RULES IMPLEMENTED IN REEDS

\begin{tabular}{|c|c|c|}
\hline $\begin{array}{c}\text { State } \\
\text { Province }\end{array}$ & $\begin{array}{c}\text { Canadian RECs } \\
\text { Accepted? }\end{array}$ & Notes \\
\hline California & Yes & Power delivered to state \\
\hline Colorado & No & - \\
\hline Massachusetts & Yes & Power delivered to ISO-NE \\
\hline Maine & No & - \\
\hline Michigan & No & - \\
\hline Minnesota & Yes & $\begin{array}{c}\text { Power must be delivered to } \\
\text { state from Manitoba }\end{array}$ \\
\hline Montana & No & - \\
\hline Nevada & No & - \\
\hline $\begin{array}{c}\text { New } \\
\text { Hampshire }\end{array}$ & No & - \\
\hline New York & No & - \\
\hline Nova Scotia & Yes & $\begin{array}{c}\text { RECs accepted from New } \\
\text { England Power Pool }\end{array}$ \\
\hline Ohio & No & - \\
\hline Oregon & Yes & $\begin{array}{c}\text { Subject to same bundling rules } \\
\text { as U.S. states }\end{array}$ \\
\hline Pennsylvania & No & - \\
\hline Rhode Island & Yes & Power delivered to ISO-NE \\
\hline Washington & Yes & Power delivered to state \\
\hline Wisconsin & Yes & Power delivered to state \\
\hline
\end{tabular}

\section{SCENARIO DESCRIPTION}

In order to demonstrate the capabilities of the tool, we model a series of scenarios that cover a wide range of possible U.S. - Canada power sector futures. The analysis portion of this work relies on the design of the reference scenario, as well as five sensitivity scenarios exploring a variety of conditions. The reference scenario is designed to serve as a point of comparison for the scenario suite and its assumptions are summarized in Table III. All scenarios use the model updates presented in the previous section and the assumptions in the reference scenario, unless otherwise noted. Scenario analysis was conducted through the 2036 ReEDS solve year to mimic the time horizon in NEB (2013) which includes results through 2035.

None of the assumptions made-in the reference scenario or sensitivities - are intended to reflect predictions of future technology or market conditions. Rather, the scenarios are designed to assess a reasonable range of future conditions. 
TABLE III. KEY REFERENCE SCENARIO ASSUMPTIONS FOR CANADA

\begin{tabular}{|c|c|}
\hline \multicolumn{2}{|c|}{ Electricity Demand } \\
\hline Load Shapes & $\begin{array}{c}\text { Provincial and zonal load shapes consistent } \\
\text { with Martinez et al. (2013) }\end{array}$ \\
\hline $\begin{array}{l}\text { Annual Demand } \\
\text { Projections }\end{array}$ & Provincial projections from NEB (2013) \\
\hline Natural Gas & $\begin{array}{l}\text { Regional pricing from AEO } 2014 \\
\text { Reference Scenario (EIA 2014) and NEB } \\
\text { (2013) }\end{array}$ \\
\hline Coal & Provincial prices from NEB (2013) \\
\hline Nuclear Fuel & National Prices from EIA (2014) \\
\hline \multicolumn{2}{|c|}{$\begin{array}{c}\text { Technology Cost and Performance } \\
\end{array}$} \\
\hline $\begin{array}{c}\text { Conventional Generation } \\
\text { Wind and Solar }\end{array}$ & $\begin{array}{c}\text { AEO } 2014 \text { Reference Scenario (EIA 2014) } \\
\text { NREL (2014) }\end{array}$ \\
\hline \multicolumn{2}{|r|}{ Infrastructure } \\
\hline $\begin{array}{c}\text { Transmission } \\
\text { Existing Capacity, } \\
\text { Expected Retirements } \\
\text { and New Infrastructure }\end{array}$ & $\begin{array}{c}\text { Consistent with Martinez et al. } 2013 \\
\text { Ventyx Energy (2014), NEB (2013) and } \\
\text { OME (2013) }\end{array}$ \\
\hline
\end{tabular}

Six scenarios are analyzed, as summarized in Table IV and are clustered into three groups to structure the analyses, through a comparison to the reference scenario ("BaseCase”).

TABLE IV. LIST OF ANALYSIS SCENARIOS

\begin{tabular}{ccc}
\hline $\begin{array}{c}\text { Scenario } \\
\text { Name }\end{array}$ & Scenario Description & $\begin{array}{c}\text { Sensitivity } \\
\text { Group }\end{array}$ \\
\hline BaseCase & Reference & - \\
\hline HiGas & $\begin{array}{c}\text { High Natural Gas Price } \\
\text { (AEO 2014 Low Oil \&Gas } \\
\text { Resource Case [EIA 2014]) }\end{array}$ & Natural gas \\
\cline { 1 - 2 } LoGas & $\begin{array}{c}\text { Low Natural Gas Price } \\
\text { (AEO 2014 High Oil \& Gas } \\
\text { Resource Case [EIA 2014]) }\end{array}$ & \\
\cline { 1 - 2 } SeparateRE & $\begin{array}{c}\text { Separate U.S. and Canada RE } \\
\text { requirement 60\% energy by 2036 }\end{array}$ & High RE \\
\cline { 1 - 2 } JointRE & $\begin{array}{c}\text { Joint U.S. and Canada RE } \\
\text { requirement 60\% energy by 2036 }\end{array}$ & \\
\hline HiCanHydro & $\begin{array}{c}\text { Canadian hydro capacity increases } \\
15 \text { GW by 2035 }\end{array}$ & $\begin{array}{c}\text { Canadian } \\
\text { hydropower }\end{array}$ \\
\hline
\end{tabular}

The first group corresponds to natural gas price sensitivities, with a high natural gas price scenario ("HiGas") and a low natural gas price scenario ("LoGas"). The only difference between these scenarios and the "BaseCase" scenario is the use of a different natural gas price projection from AEO 2014 (EIA 2014).

The second group of sensitivities presents a prescribed renewable energy ( $R E$ ) requirement, that is, RE must serve an increasing fraction of load. This requirement mimics the prescribed trajectories in NREL's Renewable Electricity Futures study (NREL 2012), reaching 60\% of substationlevel demand by RE in the year 2036. The first scenario in this sensitivity group forces the United States and Canada to follow the RE prescription independently ("SeparateRE"), while the second imposes a single RE requirement over both countries ("JointRE"), thus encouraging cooperation and an integrated approach to meeting the requirement. In both cases the RE requirements includes hydropower, wind, solar PV and CSP, geothermal and biopower.

The final scenario presents a case with higher deployment of conventional hydropower capacity in Canada through 2036
("HiCanHydro") relative to the "BaseCase" scenario. Given the lack of available data to appropriately represent the hydropower potential in Canada within the ReEDS framework, the "BaseCase" scenario enforces hydropower expansion in Canada, based on data from NEB (2013). The "HiCanHydro" scenario presents a more aggressive hydropower deployment scenario, which reaches $87 \mathrm{GW}$ of cumulative Canadian hydropower capacity by 2036 compared to $81 \mathrm{GW}$ in the "BaseCase" scenario.

\section{RESULTS}

\section{A. Reference scenario}

This section describes the results of the "BaseCase" scenario. We begin by describing the evolution of the U.S. and Canadian capacity mix (Fig. 4) mix. Given the cost and performance assumptions utilized and state RPS requirements, we observe a significant growth of wind and solar PV deployment in the United States, reaching $181 \mathrm{GW}$ and $168 \mathrm{GW}$, respectively. There is also a reduction in nuclear (from $98 \mathrm{GW}$ to $68 \mathrm{GW}$ ), coal (from $296 \mathrm{GW}$ to 229 $\mathrm{GW}$ ) and oil-gas-steam (OGS) (from $83 \mathrm{GW}$ to $5 \mathrm{GW}$ )) generation capacity driven by prescribed and lifetime retirements that do not get rebuilt. There is a moderate increase in natural gas CC capacity from (220 GW to 231 GW) and a more significant increase in natural gas combined turbine (CT) capacity (from $145 \mathrm{GW}$ to $320 \mathrm{GW}$ ). CT generators are primarily utilized to meet planning capacity reserve margins.

The capacity mix in Canada follows a similar evolution. There is a gradual decline of nuclear (from $14 \mathrm{GW}$ to 10 $\mathrm{GW}$ ), coal (from $10 \mathrm{GW}$ to $4 \mathrm{GW}$ ) and OGS (from $6 \mathrm{GW}$ to $0.6 \mathrm{GW})$ capacity, mainly due to prescribed retirements. Hydropower and gas CC capacity increases slightly (6 GW and $4 \mathrm{GW}$, respectively), whereas wind power experiences significant growth (just over $33 \mathrm{GW}$ ) and is used to meet the majority of future load growth. Again, the significant contribution of wind to new capacity additions is largely driven by the cost and performance assumptions for the different generation technologies.

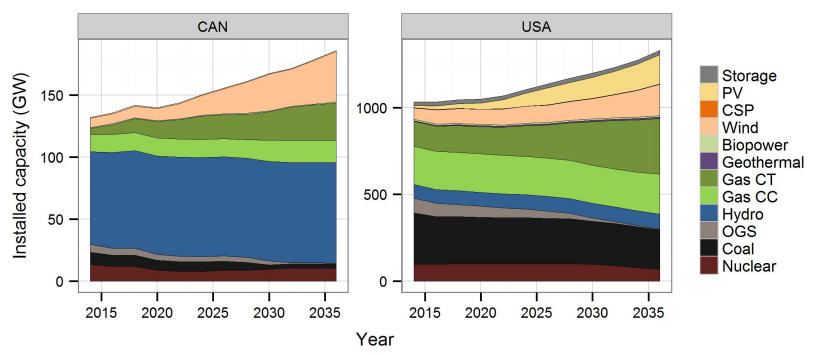

Figure 4. Capacity by generator type for the United States and Canada, "BaseCase" scenario

Figure 5 shows that net imports to the United States from Canada remain positive throughout the analysis period, although the magnitude varies. In the first half of the time horizon, the net interchange is reduced gradually as Canadian 
conventional generators are retired at a faster pace than new plants are installed, and natural gas generators on the U.S. border that initially had low capacity factors are ramped up to meet this new demand. In the last 10 years of the simulation, the net interchange increases again as prescribed retirements are less severe and more Canadian hydropower and wind capacity is installed. For comparison purposes, the net interchanges presented in NEB (2013) are typically in the 40$50 \mathrm{TWh}$ range annually for the same timeframe.

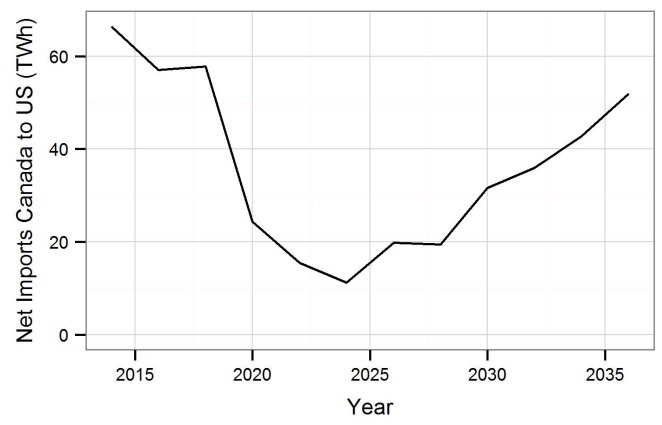

Figure 5. Net energy interchange between Canada and the United States, "BaseCase" scenario

Figure 6 shows the breakdown of net interchange by "zones" across the border. In the east, ISO New England (ISO-NE) and New York ISO (NYISO) import energy throughout the entire study period through 2036, with NYISO increasing that share in the later simulation years. However, in the Western Interconnection we see increasing net imports to Canada from the United States, mainly driven by the rapid load growth in Alberta, which is satisfied partially by U.S. generation. In the Midcontinent ISO (MISO) we initially observe imports from Canada that reverse direction around 2026 and thereafter net to nearly zero. This is partially driven by early nuclear retirements in Ontario (which are later replaced by new capacity), modest wind deployment in Ontario and existing unused gas CC capacity in the United States, along with ample transmission capacity.

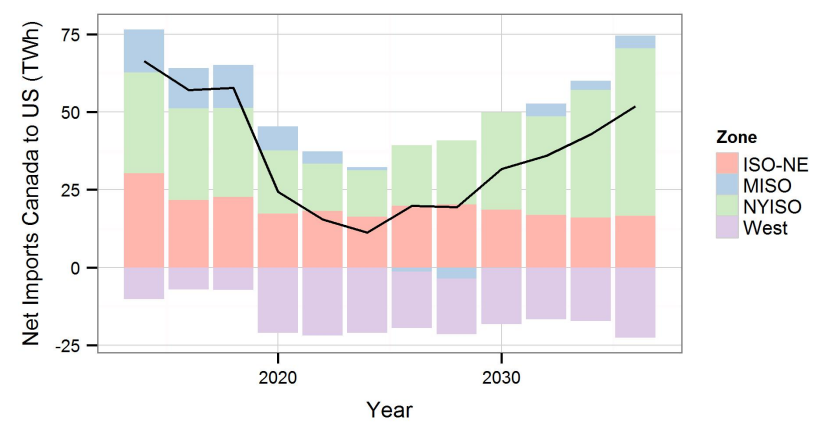

Figure 6. Net energy interchange between countries (line) along with net interchange by zone (bars), "BaseCase" scenario

\section{B. Summary of sensitivities}

This section summarizes the results for all previously presented scenarios. First, we focus on the final generation mix by type by the end of the analysis period, presented in Fig. 7. For Canada, the main difference across scenarios is the amount of wind and gas CC capacity. There is more wind installed in cases with favorable conditions, such as the "HiGas" and "JointRe" scenarios and it decreases significantly in the "LoGas" and "SeparateRE" scenarios. The "LoGas" scenario sees a significant increase in gas CC capacity and generation. Almost all the other sensitivities see smaller levels of gas CC generation, even when installed gas CC capacity remains the same.

The changes in the United States are similar. Wind and solar capacity increase in the "HiGas" and high RE scenarios. Those scenarios see a reduction in generation from gas CC (and coal in the case of the RE scenarios). In contrast, the "LoGas" scenario exhibits an increase in gas CC capacity and generation.

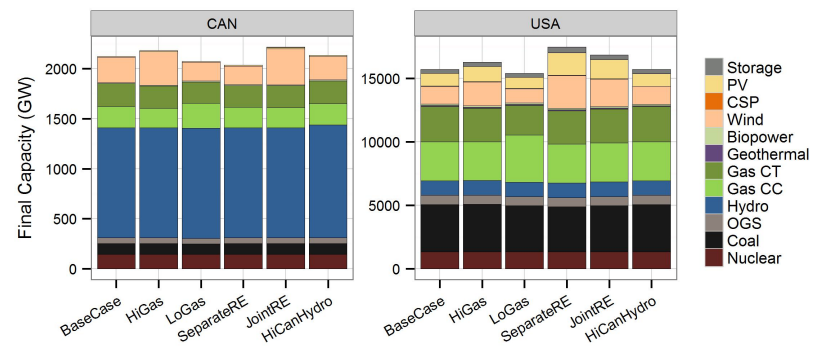

Figure 7. Capacity by type and country for all scenarios in 2036

The level of overall transmission construction is similar for most of the scenarios (Fig. 8). The "HiCanHydro" scenario shows slightly higher builds, which are concentrated mainly in the west. For the most part, net imports from Canada decrease in early years, but generally stay positive for most scenarios. Net interchanges in the "SeparateRE" scenario actually continue the downward trend and, eventually, show a net import to Canada from the United States (Fig. 9). This is driven by the need to install RE generation in the United States to meet its own RE requirement, while the Canadian requirement is never binding. This also causes the scenario to have the smallest development of new transmission across the border, particularly in the interface into NYISO. The exchange under the two natural gas sensitivities sees a reduction in net energy imports and, consequently, there is a reduction in the international capacity deployed, particularly in the western interconnection.

Finally, the comparison of $\mathrm{CO}_{2}$ emissions by country across scenarios is also interesting (Fig. 10). In Canada, $\mathrm{CO}_{2}$ emissions decrease for most scenarios, as more generation comes from wind and hydropower. This decrease is more pronounced in the "HiGas" and high RE scenarios. For the "LoGas" scenario, Canadian $\mathrm{CO}_{2}$ emissions are slightly higher than all other cases because there is a shift from wind generation to gas CC. For the United States, the most substantial $\mathrm{CO}_{2}$ reductions relative to the reference scenario appear in the high RE scenarios, followed by the "LoGas" 
scenario due to some coal-to-gas switching, increased wind deployment, and also because more energy is imported from Canada.

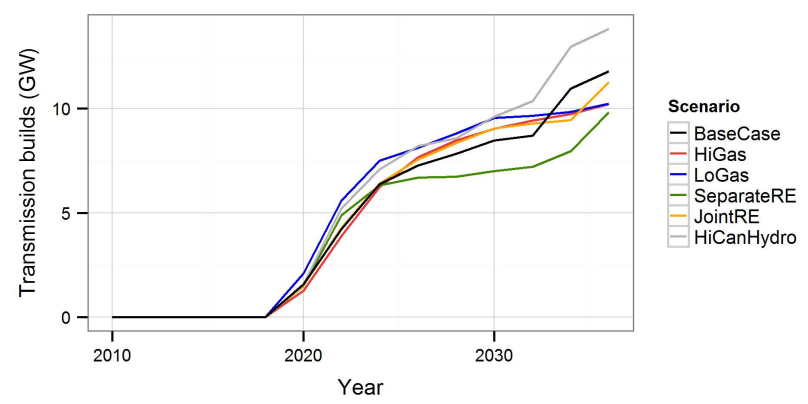

Figure 8. New international transmission capacity for all scenarios

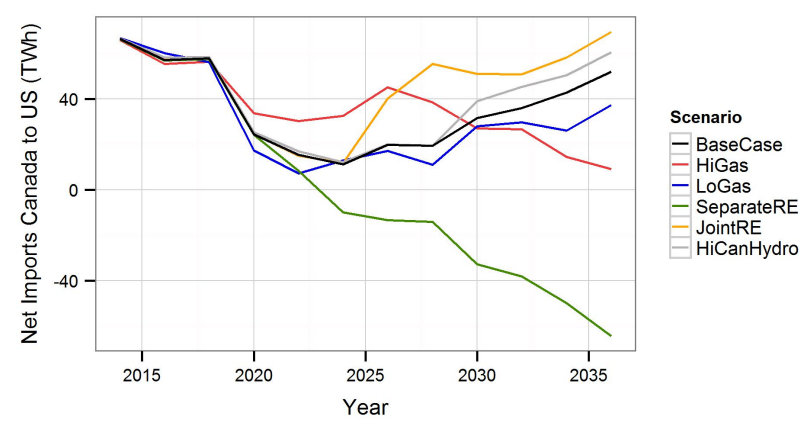

Figure 9. Net energy interchange between countries for all scenarios

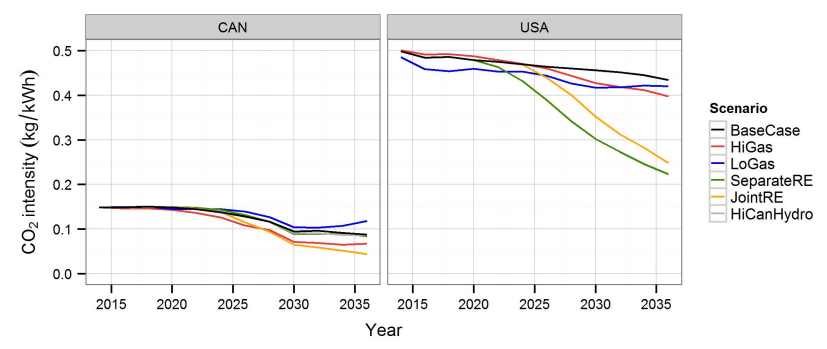

Figure $10 . \mathrm{CO}_{2}$ intensity by country for all scenarios

\section{CONCLUSIONS AND NeXT STEPS}

This paper documents a development effort to represent the U.S. and Canadian electricity sectors in a single planning model, through the NREL ReEDS model. Robust data sources that are used to formulate the model are provided.

A reference scenario is presented and analyzed in the analysis portion of this report. Five additional sensitivity scenarios are also presented.

The reference scenario results show a significant increase in wind generation in both the United States and Canada with a gradual retirement of coal and nuclear energy. The evolution of net energy and firm capacity exchange is very dynamic through the span of the analysis period and drives significant investment in transmission capacity across the border, almost doubling the existing capacity of transmission lines. The exchange of energy is driven by regional stories.
ISO-NE and NYISO import energy throughout the analysis period. However, in the Western Interconnection we observe increasing imports to Canada from the United States, whereas the exchanges with MISO switch directions.

The five sensitivities present distinct evolutions of the U.S. and Canadian power systems. Higher natural gas prices result in higher levels of RE deployment in both countries and vice versa. Natural gas price projections have an effect on the interchange of energy between regions, driven by competition between gas CC and wind generation and the availability of those resources in different regions. However, transmission builds across the border do not vary substantially. The RE requirement scenarios exhibit distinct locational distributions of wind and PV deployment, depending on whether the requirement applies to each country separately or individually. Higher deployment of Canadian hydropower partially displaces some Canadian wind and U.S. gas CC deployment.

The work summarized in this report represents a unique approach to simulation of planning and operations of the electric system across the United States and Canada. This scenario analysis hints at the potential for Canada and the United States to benefit through collaborative actions, such as shared greenhouse-gas mitigation goals and transmission planning. Future analysis will expand the scenario-based approach presented here and focus on the characterization of results as a function of input modification.

\section{ACKNOWLEDGMENT}

This work was supported by the U.S. Department of Energy under Contract No. DE-AC36-08-GO28308 with the National Renewable Energy Laboratory.

\section{REFERENCES}

CEA (Canadian Electricity Association). 2010. The Integrated Electricity System: Sustainable Electricity as the Foundation for Economic Recovery in North America. Ottawa, Ontario, Canada: Canadian Electricity Association. Accessed July 2014. http://www.electricity.ca/media/pdfs/economic/canada us affairs/CEA Enhancing_2010 final.pdf

DOE (U.S. Department of Energy). 2008. 20\% Wind Energy by 2030: Increasing Wind Energy's Contribution to U.S. Electricity Supply. Washington, D.C.: U.S. Department of Energy Office of Energy Efficiency and Renewable Energy. Accessed October 2014. www.20percentwind.org/20percent_wind_energy report_revOct08.pdf. . 2012. SunShot Vision Study. NREL/BK-5200-47927; DOE/GO102012-3037. Washington, D.C.: U.S. Department of Energy Office of Energy Efficiency and Renewable Energy. Accessed October 24, 2014. http://www.nrel.gov/docs/fy12osti/47927.pdf.

- 2015. Wind Vision: A New Era for Wind Power in the United States. Washington, D.C. http://www.energy.gov/windvision.

EIA (U.S. Energy Information Administration). 2014. Annual Energy Outlook 2014. DOE/EIA-0383(2014). Washington, D.C.: Energy Information Administration.

Environment Canada. 2008. "Canadian Wind Energy Atlas.” Fredericton, New Brunswick, Canada: Environment Canada. Accessed November 2014. http://www.windatlas.ca

Logan, Jeffrey, Anthony Lopez, Trieu Mai, Carolyn Davidson, Morgan Bazilian, and Douglas Arent. 2013. "Natural Gas Scenarios in the U.S. Power Sector.” Energy Economics 40:183-95. Accessed October 2014. http://dx.doi.org/10.1016/j.eneco.2013.06.008. 
Lopez, Anthony, Billy Roberts, Donna Heimiler, Nate Blair, and Gian Porro, 2012. U.S. Renewable Energy Technical Potentials: A GIS-Based Analysis. NREL/TP-6A20-51946. Golden, CO: National Renewable Energy Laboratory.

Mai, Trieu, David Mulcahy, M. Maureen Hand, and Samuel F. Baldwin. 2014. "Envisioning a Renewable Electricity Future for the United States.” Energy 65:1;374-86. Accessed December 2014. http://dx.doi.org/10.1016/j.energy.2013.11.029.

Martinez, Andrew, Kelly Eurek, Trieu Mai, and Andrew Perry. 2013. Integrated Canada-U.S. Power Sector Modeling with the Regional Energy Deployment System (ReEDS). NREL/TP-6A2056724. Golden, CO: National Renewable Energy Laboratory.

NEB (National Energy Board). 2013. Canada's Energy Future 2013 Energy Supply and Demand Projections to 2035. Calgary, Alberta, Canada: National Energy Board. Accessed October 20, 2014. https://www.neb-one.gc.ca/nrg/ntgrtd/ftr/2013/2013nrgftr-eng.pdf.

NERC (North American Electric Reliability Corporation), 2010. 2010 LongTerm Reliability Assessment, Princeton, NJ: Oct. 2010, www.nerc.com/files/2010\%20LTRA.pdf.

NREL (National Renewable Energy Laboratory). 2012. Renewable Electricity Futures Study. Edited by M.M. Hand, S. Baldwin, E. DeMeo, J.M. Reilly, T. Mai, D. Arent, G. Porro, M. Meshek, D. Sandor. 4 vols. NREL/TP-6A20-52409. Golden, CO: National Renewable Energy Laboratory.

-. 2014. Annual Technology Baseline and Standard Scenarios. Accessed November

2014. http://www.nrel.gov/analysis/data tech baseline.html

OME (Ontario Ministry of Energy). 2013. Achieving Balance: Ontario's Long Term Energy Plan. Ontario, Canada: Ontario Ministry of Energy. Accessed October 2014. http://www.energy.gov.on.ca/en/files/2014/10/LTEP_2013_English_W EB.pdf.

Short, Walter, Patrick Sullivan, Trieu Mai, Matthew Mowers, Caroline Uriarte, Nate Blair, Donna Heimiller, and Andrew Martinez. 2011. Regional Energy Deployment System (ReEDS). NREL/TP-6A2046534. Golden, CO: National Renewable Energy Laboratory. Accessed October 2014: http://www.nrel.gov/analysis/reeds/pdfs/reeds documentation.pdf.

Ventyx Energy, 2014. Ventyx Energy Velocity Suite, accessed October, 2014.
Zinaman, Owen, Eduardo Ibanez, Donna Heimiler, Kelly Eurek, and Trieu Main, 2015. Modeling the Integrated Expansion of the Canadian and U.S. Power Sectors with the Regional Energy Deployment System (ReEDS). NREL/TP-6A20-63797. Golden, CO: National Renewable Energy Laboratory.

Eduardo Ibanez received in the Diploma degree in Industrial Engineering from Universidad Pública de Navarra, Pamplona, Spain. He graduated from Iowa State University, Ames, IA with a Ph.D. degree in Electrical Engineering and a M.Sc. degree in Statistics. He is a senior engineer with Energy Consulting, Schenectady, NY. Previously, he was a supervisor and senior engineer at the Transmission and Grid Integration Group at the National Renewable Energy Laboratory, Golden, CO, USA. His research interests include studying high levels of renewable energy penetration, transmission planning, and the energy and transportation systems integration.

Owen Zinaman is a power system analyst in the Energy Forecasting and Modeling Group in the Strategic Energy Analysis Center at the National Renewable Energy Laboratory. He also serves as the Technical Lead of the 21st Century Power Partnership, a multilateral technical assistance and electric sector capacity-building program operating in South Africa, India, and Mexico on behalf of the Clean Energy Ministerial. He received his Masters degree in Nuclear Engineering and Radiological Sciences from the University of Michigan, with focuses in Computational Reactor Physics and Science \& Technology Public Policy. 